\title{
The effect of strain relaxation on electron transport in undoped $\mathrm{Al}_{0.25} \mathrm{Ga}_{0.75} \mathrm{~N} / \mathrm{GaN}$ heterostructures
}

\author{
S.B. Lişesivdin ${ }^{\mathrm{a}, *}$, A. Yıldız ${ }^{\mathrm{b}}$, S. Acar ${ }^{\mathrm{a}}$, M. Kasap ${ }^{\mathrm{a}}$, S. Özçelik ${ }^{\mathrm{a}}$, E. Özbay ${ }^{\mathrm{c}}$ \\ ${ }^{\mathrm{a}}$ Department of Physics, Gazi University, Ankara 06500, Turkey \\ ${ }^{\mathrm{b}}$ Department of Physics, Faculty of Science and Arts, Ahi Evran University, 40100 Kirsehir, Turkey \\ ${ }^{\mathrm{c}}$ Department of Physics, Department of Electrical-Electronics Engineering, Nanotechnology Research Center, Bilkent University, Ankara, Turkey
}

Received 14 November 2006; received in revised form 6 April 2007; accepted 30 May 2007

\begin{abstract}
The two-dimensional electron gas (2DEG) transport properties of two-step growth undoped $\mathrm{Al}_{0.25} \mathrm{Ga}_{0.75} \mathrm{~N} / \mathrm{GaN}$ heterostructures with semi-insulating buffer, grown by MOCVD, were investigated in a temperature range of 20-350 K. Using the quantitative mobility spectrum analysis (QMSA) method, it was shown that significant parallel conduction does not occur in worked structures. In-plain growth axis strains are calculated using the total polarization-induced charge density taken as the sheet carrier density measured from the Hall effect. It was found that the calculated strain values are in good agreement with those reported. Influences of the two-step growth parameters such as growth ramp time, the annealing temperature of the GaN nucleation layer on the mobility, and density of the 2DEG are also discussed.
\end{abstract}

(C) 2007 Elsevier B.V. All rights reserved.

PACS: 73.40.-c; 73.61.-r; 73.61.Ey; 61.72.Hh

Keywords: AlGaN/GaN; Heterostructure; Strain; QMSA; MOCVD

\section{Introduction}

Due to the rapid increase of wireless communication needs, semiconductor power amplifiers with high frequency and power capabilities are in high demand. Wide band gap compound semiconductors are the most promising alternative over $\mathrm{Si}$ and even GaAs. $\mathrm{Al}_{x} \mathrm{Ga}_{1-x} \mathrm{~N} / \mathrm{GaN}$ heterostructures [1] have been demonstrated for these power applications at high temperatures with a high cutoff frequency and a large sheet carrier density [2-8]. $\mathrm{Al}_{x} \mathrm{Ga}_{1-x} \mathrm{~N} / \mathrm{GaN}$ heterostructures have electron mobilities of $\sim 1500 \mathrm{~cm}^{2} / \mathrm{V} \mathrm{s}$, average electron transit velocities of $\sim 1.25 .10^{7} \mathrm{~cm} / \mathrm{s}$, and very good high frequency response. Unlike $\mathrm{Si}$ and $\mathrm{GaAs}$, GaN based heterostructures have strong spontaneous and piezoelectric polarization, which causes two-dimensional electron gas (2DEG) with high sheet carrier density values, without intentional doping.

\footnotetext{
*Corresponding author.

E-mail address: sblisesivdin@gmail.com (S.B. Lișesivdin).
}

It is well known that the nucleation layer is one of the important factors that determine the quality of the epitaxial layers. Certain improvements can be achieved in structural, electrical, and optical properties when a nucleation layer is grown between the epilayers and substrate. The main function of the nucleation layer is to supply nucleation centers with the same orientation with the substrate and to assist the lateral growth of epilayers with large grain sizes. Because of this, the growth procedure of the nucleation layer is one of the primary effects for the quality of the entire material structure, and therefore, the device's performance [9]. Early studies reported that the GaN nucleation layers formed amorphously [10,11]. Recently, the RHEED, XRD, and TEM studies on GaN have shown that the zinc blende and wurtzite phases are presented in the nucleation layers $[10,12,13]$. It is also reported that the nucleation layers consist of piled faults and the amount of these piles could be altered with annealing at high temperatures $[13,14]$. To have a better $2 \mathrm{DEG}$ at the $\mathrm{AlGaN} / \mathrm{GaN}$ interface, the 
composition transition at the interface must be sudden and the interface must be horizontally smooth. It is known that [15-17] the interface roughness has an important effect on 2DEG properties, such as the mobility and carrier density. In addition to this, due to lattice mismatching, a large strain can be constructed at the $\mathrm{Al}_{x} \mathrm{Ga}_{1-x} \mathrm{~N} / \mathrm{GaN}$ interface, in which this raises the question of strain relaxation even for a thin epitaxial $\mathrm{GaN}$ or the $\mathrm{Al}_{x} \mathrm{Ga}_{1-x} \mathrm{~N}$ layers. The strain relaxation leads more roughness at the interface [18], so lower 2DEG must be expected. Therefore, the investigations of strain and strain relaxation are important not only for the understanding of the structure properties but also the transport properties of III-V nitride heterostructures.

In this work, we extract the existence of the 2DEG and show that the parallel conduction is insignificant in $\mathrm{Al}_{0.25} \mathrm{Ga}_{0.75} \mathrm{~N} / \mathrm{GaN}$ heterostructures from the temperature and magnetic field-dependent Hall data using the quantitative mobility spectrum analysis (QMSA) method. The in-plane and growth axis strains were also calculated from the polarization-induced carrier density. With these results, transport and strain properties of two-step growth undoped $\mathrm{Al}_{0.25} \mathrm{Ga}_{0.75} \mathrm{~N} / \mathrm{GaN}$ heterostructures were compared.

\section{Experiment}

The GaN epilayers were grown on $c$-plane $\left(\begin{array}{llll}0 & 0 & 0 & 1\end{array}\right)$ sapphire $\left(\mathrm{Al}_{2} \mathrm{O}_{3}\right)$ substrates in a low-pressure metalorganic chemical vapor deposition (MOCVD) reactor. Prior to epilayer growth, the sapphire substrates were cleaned in $\mathrm{H}_{2}$ ambient at $1100^{\circ} \mathrm{C}$, and then a 25 -nm-thick low-temperature (LT) $\mathrm{GaN}$ nucleation layer was grown at $500^{\circ} \mathrm{C}$. The reactor pressure was set to $50 \mathrm{mbar}$ during the substrate cleaning and nucleation growth. After the deposition of the LT-GaN nucleation layer, the wafers were heated to a high temperature for annealing. The resistivity and surface roughness of the GaN buffer layer can be changed by the two-step growth method with adjusting the ramp time, nucleation layer (NL) annealing temperature, and NL thickness $[19,20]$. For B-027 and B-060 samples, the twostep growth process was applied with the ramp times 2.5 and $5 \mathrm{~min}$, and the annealing temperatures 1100 and $1050{ }^{\circ} \mathrm{C}$, respectively. Approximately a $2.5-\mu \mathrm{m}$-thick GaN layer was deposited on the annealed NLs using constant growth conditions. Finally, a 25-nm-thick $\mathrm{Al}_{0.25} \mathrm{Ga}_{0.75} \mathrm{~N}$ with $3 \mathrm{~nm} \mathrm{GaN}$ cap layers were grown. The details of samples are given in Fig. 1.

For the resistivity, the magnetoresistivity and Hall effect measurements by the van der Pauw method were performed in which the square shaped $\left(5 \times 5 \mathrm{~mm}^{2}\right)$ samples were prepared with $\mathrm{Ti} / \mathrm{Al} / \mathrm{Ni} / \mathrm{Au}$ evaporated dot contacts in the corners. Ohmic behavior of the contacts was confirmed by the current-voltage $(I / V)$ characteristics. The measurements were taken in a temperature range of $20-350 \mathrm{~K}$ using a Lakeshore Hall effect measurement system (HMS). At temperature steps, the Hall coefficient and resistivity (with $0.2 \%$ accuracy) were measured for

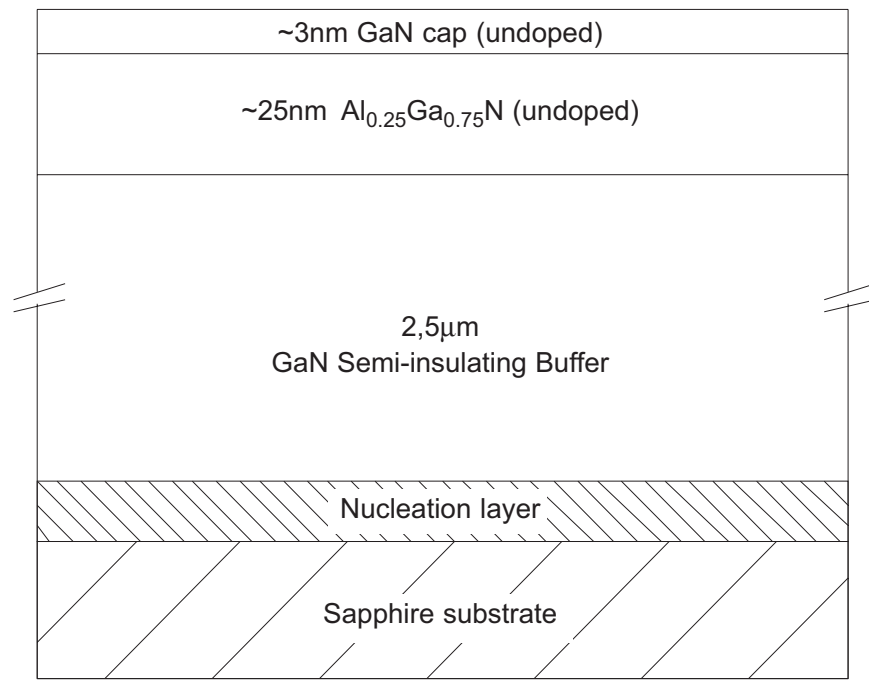

Fig. 1. Layer structure of the two $\mathrm{Al}_{0.25} \mathrm{Ga}_{0.75} \mathrm{~N} / \mathrm{GaN}$ heterostructures samples used in the study.

both current directions, magnetic field polarizations, and all possible contact configurations at the 31 magnetic field steps between 0 and $1.5 \mathrm{~T}$. The magnetic field-dependent data has been analyzed using the QMSA software provided by Lakeshore.

\section{Results and discussion}

Fig. 2(a) and (b) shows the temperature dependence of resistivity, and carrier concentration and Hall mobility, respectively, for B-027 and B-060 samples in the temperature range $20-350 \mathrm{~K}$. Both samples represent a similar temperature dependence of resistivity, Hall mobility and carrier density. It is noted that the same results were obtained for the measurements carried out at either the increasing or decreasing temperature. At high temperatures, the resistivity sharply decreases with decreasing temperature while it is independent of temperature at low temperatures $(<100 \mathrm{~K})$. However, the B-060 exhibits a slightly higher resistivity at high temperatures and slightly lower resistivity at low temperatures than the resistivity of B-027. This behavior is reflected on the temperature dependence of mobility. According to the device fabrication results, the buffer of B-060 is more conductive and has a smoother surface according to B-027.

As can be seen from Fig. 2(b), for both the samples, the measured sheet electron density and Hall mobility are nearly independent of temperature below $100 \mathrm{~K}$, where impurity and interface roughness scatterings would be expected to dominate. This behavior is typical of $2 \mathrm{DEG}$ structures. Above $100 \mathrm{~K}$, Hall mobility decreases with increasing temperature with a temperature dependence $\sim T^{-3 / 2}$, which is the typical temperature dependence for optical phonon scattering mobility. The sheet carrier density still tends to be a constant that is further confirmation of the 2DEG even at high temperatures. Both samples can be accepted to have same impurity values 
so that they have the same limiting background impurity scattering, which results from the low-temperature mobility difference mostly caused by interface roughness. In the case of carrier densities above $7-8 \times 10^{12} \mathrm{~cm}^{-2}$, the electron wave functions can penetrate further into the $\mathrm{AlGaN}$
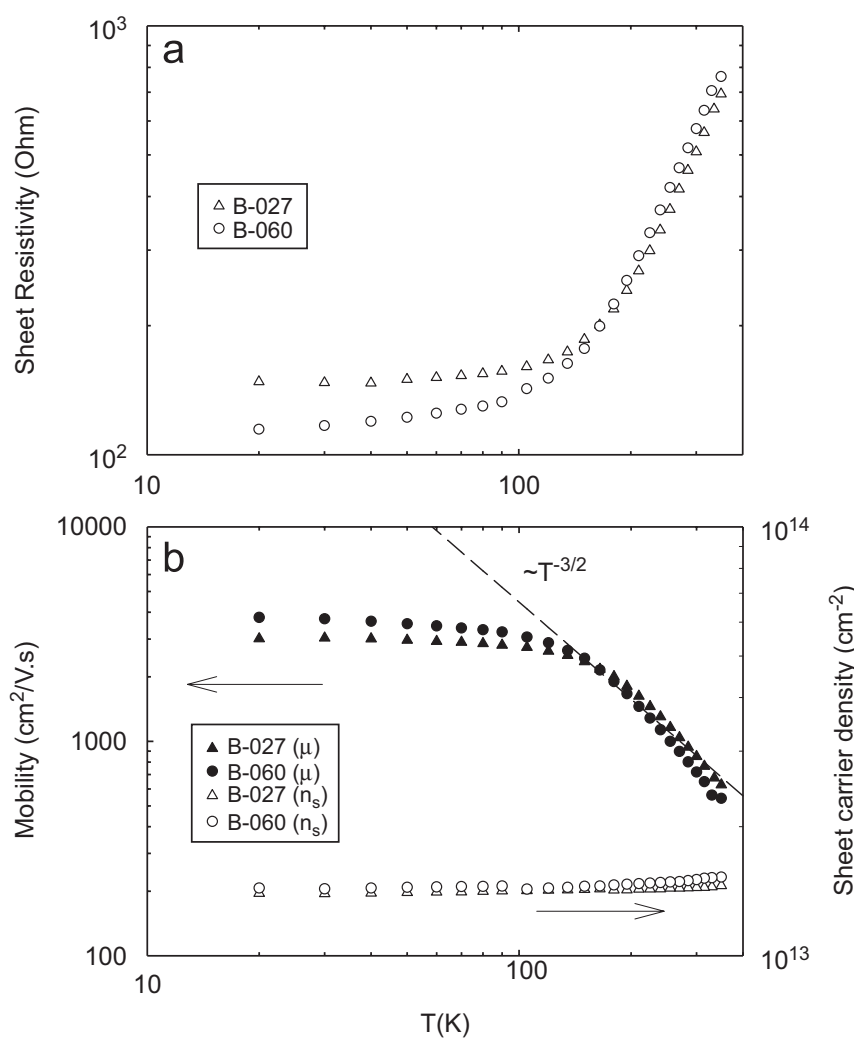

Fig. 2. Temperature dependence of sheet resistivities (a) and Hall mobilities and sheet carrier densities (b) for the B-027 and B-060 samples. barrier. This causes the interface roughness scattering to become more effective [17].

The room temperature electron Hall mobilities are 850 and $719 \mathrm{~cm}^{2} / \mathrm{V} \mathrm{s}$, and the sheet carrier densities are $1.44 \times 10^{13} \mathrm{~cm}^{-2}$ and $1.50 \times 10^{13} \mathrm{~cm}^{-2}$, for $\mathrm{B}-027$ and B-060, respectively. The high values of sheet carrier density are caused by spontaneous and piezoelectric polarization fields [21,22]. At $20 \mathrm{~K}$, the electron mobility is as high as 3013 and $3780 \mathrm{~cm}^{2} / \mathrm{V} \mathrm{s}$ for B-027 and B060, respectively. These results show that nominal $\mathrm{AlGaN} / \mathrm{GaN}$ heterointerface were grown on sapphire substrates.

Dziuba et al. [23] used the QMSA method, which is a magnetic field-dependent Hall data analyzing method, for extracting the parallel channels. The QMSA method can enable the separation of the individual carrier species in a multicarrier or multichannel semiconductor [24]. Mobility and carrier conduction of each carrier or channel can be extracted using this method. In order to determine if there is any significant parallel conduction in our samples, magnetic field-dependent Hall effect measurement results were used in the QMSA method. Mobility spectrums are calculated at each temperature step. The calculated mobility spectrums are joined in Fig. 3 and showed as contour graphics where the $z$-axis is conductivity. Actually in the literature, mobility spectrums are investigated as conductivity versus mobility $[25,26]$, and the carrier peak intervals are accepted as single carriers. As seen in Fig. 3, highly conductive $2 \mathrm{DEG}$ can be seen below $100 \mathrm{~K}$. Above $100 \mathrm{~K}$, the behavior is typical of 2DEG showing a strong influence of phonon scattering. In both samples, there is no significant parallel channel contribution to the total conduction. On the other hand, in our previous work [27], thermally activated bulk carriers, which have a negligible effect on the total sheet carrier density, were presented. It has also been shown that these carriers were a

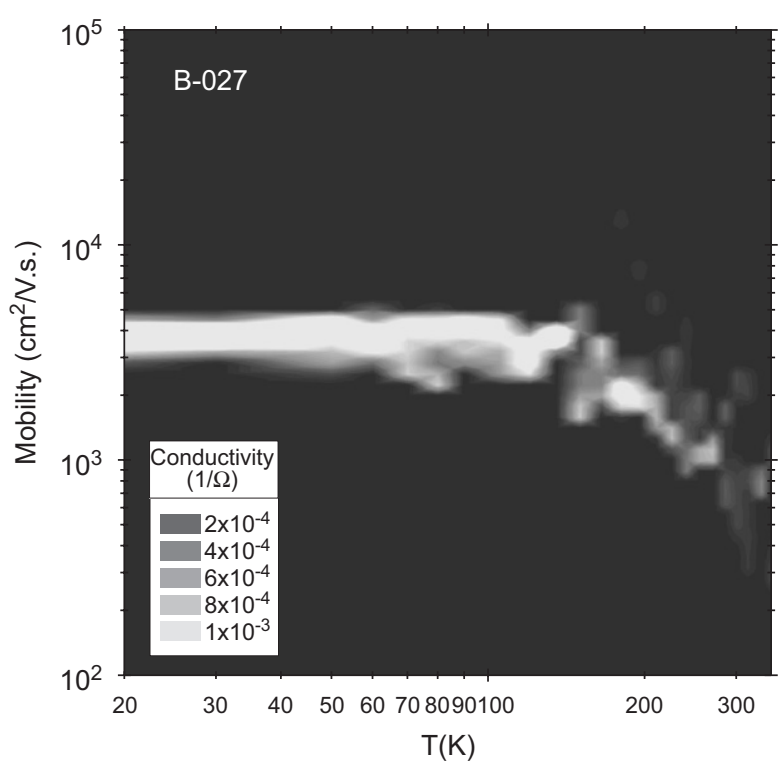

b

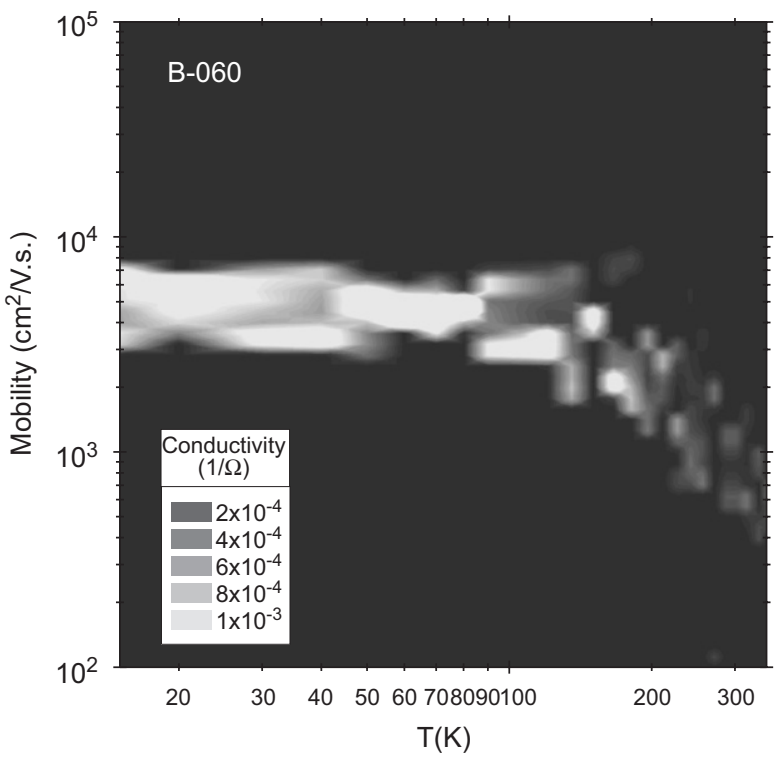

Fig. 3. Temperature dependence of electron mobility spectrums for the (a) B-027 and (b) B-060 samples. 
totally freeze out at $200 \mathrm{~K}$. Therefore, it can be considered that the conductivity values in Fig. 3 only belong to 2DEG. And, it is found that there is no clear contribution to the conductivity from the hole species. The temperature dependence of mobilities obtained from QMSA (Fig. 3) is in a very good agreement with the single-field Hall mobilities taken at $0.5 \mathrm{~T}$, which are shown in Fig. 2(b). These results support the fact that there is a no-parallel channel contribution to the total conduction below $100 \mathrm{~K}$ while the thermally activated bulk carriers have negligible contribution to total conductivity above $200 \mathrm{~K}$.

In the case of a no significant parallel conduction, all carriers in 2DEG in $\mathrm{AlGaN} / \mathrm{GaN}$ heterostructures are induced by strong spontaneous and piezoelectric polarization fields $[25,26,28]$. In the absence of external electric fields, the total polarization is the sum of these fields: $P=P_{\mathrm{SP}}+P_{\mathrm{PE}}$. Therefore, it is accepted that the measured sheet carrier density $\left(n_{\mathrm{s}}\right)$ is only due to the total polarization-induced sheet charge density $\left(n_{\mathrm{s}}=\sigma(x) / e\right)$. The spontaneous polarization along the [0 $\left.\begin{array}{llll}0 & 0 & 1\end{array}\right]$ axis can be written as $P_{\mathrm{SP}}=P_{\mathrm{SP}} z$. According to Ambacher et al. [16], the amount of polarization-induced sheet charge density of the undoped pseudomorphic $\mathrm{GaN} / \mathrm{Al}_{x} \mathrm{Ga}_{1-x} \mathrm{~N} /$ $\mathrm{GaN}$ heterostructure can be calculated using

$|\sigma(x)|=\left|P_{\mathrm{PE}}\left(\mathrm{Al}_{x} \mathrm{Ga}_{1-x} \mathrm{~N}\right)+P_{\mathrm{SP}}\left(\mathrm{Al}_{x} \mathrm{Ga}_{1-x} \mathrm{~N}\right)-P_{\mathrm{SP}}(\mathrm{GaN})\right|$,

where spontaneous polarization and piezoelectric polarization are defined as

$$
\begin{aligned}
& P_{\mathrm{SP}}\left(\mathrm{Al}_{x} \mathrm{Ga}_{1-x} \mathrm{~N}\right)=-0.052 x-0.029 \quad\left(\mathrm{C} / \mathrm{m}^{2}\right), \\
& P_{\mathrm{PE}}\left(\mathrm{Al}_{x} \mathrm{Ga}_{1-x} \mathrm{~N}\right)=2 \varepsilon_{x}\left\{e_{31}(x)-e_{33}(x) \frac{C_{13}(x)}{C_{33}(x)}\right\} \quad\left(\mathrm{C} / \mathrm{m}^{2}\right)
\end{aligned}
$$

with piezoelectric and elastic constants:

$$
\begin{aligned}
& e_{31}(x)=-0.11 x-0.49 \quad\left(\mathrm{C} / \mathrm{m}^{2}\right), \\
& e_{33}(x)=0.73 x+0.73 \quad\left(\mathrm{C} / \mathrm{m}^{2}\right), \\
& C_{13}(x)=5 x-103 \quad(\mathrm{GPa}), \\
& C_{33}(x)=-32 x+405 \quad(\mathrm{GPa}) .
\end{aligned}
$$

These polarizations and constants are also temperature dependent. However, we assume that these temperature dependences are negligible for our calculations. Piezoelectric polarization $\left(P_{\mathrm{PE}}\left(\mathrm{Al}_{x} \mathrm{Ga}_{1-x} \mathrm{~N}\right)\right)$ can be calculated from Eq. (1) using the polarization-induced sheet charge density taken as the sheet carrier density measured from Hall effect $\left(\sigma(x)=n_{\mathrm{s}} e\right)$, and spontaneous polarizations $\left(P_{\mathrm{SP}}\left(\mathrm{Al}_{x} \mathrm{Ga}_{1-x} \mathrm{~N}\right)\right.$ and $\left.P_{\mathrm{SP}}(\mathrm{GaN})\right)$ are obtained from Eq. (2). Therefore, an in-plane strain can be written from Eq. (3) as

$\varepsilon_{x}=\frac{P_{\mathrm{PE}}\left(\mathrm{Al}_{x} \mathrm{Ga}_{1-x} \mathrm{~N}\right)}{2\left\{e_{31}(x)-e_{33}(x)\left(C_{13}(x) / C_{33}(x)\right)\right\}}$.
In this work, the in-plane strain $\left(\varepsilon_{x}=\varepsilon_{y}\right)$ is assumed to be isotropic and the third polarization component induced by shear strain $\left(e_{15}\right)$ is not discussed. The growth-axis strain $\left(\varepsilon_{z}\right)$ is related with the in-plane strain $\left(\varepsilon_{x}\right)$ in wurtzite $\mathrm{GaN}$ with $\varepsilon_{z}=-2\left(C_{13} / C_{33}\right) \varepsilon_{x}$. In the calculations, $x=0.25$ is used as the composition ratio.

The calculated temperature-dependent in-plane and growth-axis strains are shown in Fig. 4. Negative strain means compression in the growth-axis, and positive strain means tensile in the in-plane direction. The calculated strains values are of the same order of magnitude as found in variety $\mathrm{AlGaN} / \mathrm{GaN}$ structures [18,29]. However, below $100 \mathrm{~K}$, the derived strain values using the sheet carrier density measured from the Hall effect are in good agreement with the temperature-dependent theoretical strain calculations (dashed lines in Fig. 4) using the temperature-dependent lattice parameters given by Iwanaga et al. [30]. Above $100 \mathrm{~K}$, thermally activated bulk carriers cause a small deviation from the theoretical prediction. These deviations are about $6.02 \%$ and $13.29 \%$ for B-027 and B-060, respectively. In addition to this, the device fabrication results showed that the buffer of B-060 is more conductive with respect to B-027. Therefore, one can consider that B-060 have a slightly higher bulk carrier density than that of B-027. It is easy to see that there is a more strain in B-060 than that of B-027 in both inplane and growth-axis directions. This is due to the difference in the growth conditions that can cause an elastic strain relaxation formation at the interface of B-027. Wickenden et al. have also reported a significant reduction in XRD determined strain as the annealing temperature was increased [29]. Reduction in the strain is generated by the elastic strain relaxation at $\mathrm{Al}_{0.25} \mathrm{Ga}_{0.75} \mathrm{~N} / \mathrm{GaN}$ interface. It can be clearly seen from Figs. 2(b) and 4 that the strain relaxation of B-027 causes a lower 2 DEG mobility

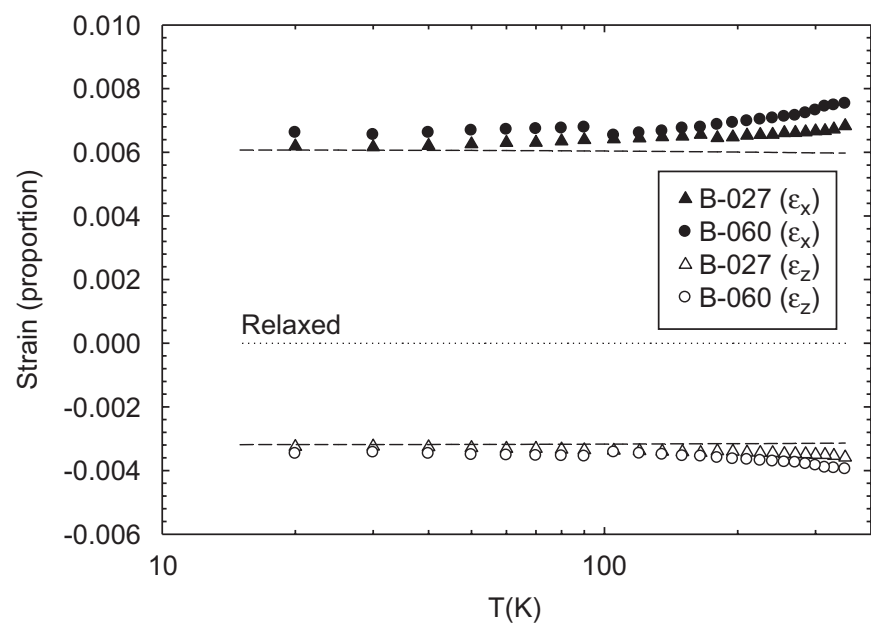

Fig. 4. The temperature-dependent in-plane strain $\left(\varepsilon_{x}\right)$ and growth-axis strain $\left(\varepsilon_{z}\right)$ of the pseudomorphic B-027 and B-060 samples. Symbols represent the calculated strains using the measured Hall data. The dashed lines show the calculated strains using the temperature dependent lattice parameters. Dotted line shows no-strain condition. 
Table 1

The growth parameters, the measured mobility and carrier densities, and the calculated strains of the studied samples

\begin{tabular}{|c|c|c|c|c|c|c|c|}
\hline Sample & $\begin{array}{l}\text { Growth ramp } \\
\text { time }(\mathrm{min})\end{array}$ & $\begin{array}{l}\text { Annealing } \\
\text { temperature }\left({ }^{\circ} \mathrm{C}\right)\end{array}$ & $\begin{array}{l}\text { Mobility at } \\
20 \mathrm{~K}\left(\mathrm{~cm}^{2} / \mathrm{V} \mathrm{s}\right)\end{array}$ & $\begin{array}{l}n_{\mathrm{s}} \text { at } 300 \mathrm{~K} \\
\left(10^{13} \mathrm{~cm}^{-2}\right)\end{array}$ & $\begin{array}{l}\varepsilon_{x} \text { at } 100 \mathrm{~K} \\
\left(\times 10^{-3}\right)\end{array}$ & $\begin{array}{l}\varepsilon_{z} \text { at } 100 \mathrm{~K} \\
\left(\times 10^{-3}\right)\end{array}$ & $\begin{array}{l}\text { Decrease in strain } \\
350-100 \mathrm{~K}(\%)\end{array}$ \\
\hline B-027 & 2.5 & 1100 & 3013 & 1.44 & 6.3635 & -3.3858 & 6.02 \\
\hline B-060 & 5 & 1050 & 3780 & 1.5 & 6.6776 & -3.4146 & 13.29 \\
\hline
\end{tabular}

and sheet carrier density below $100 \mathrm{~K}$. Shen et al. [28] also have reported similar findings for $\mathrm{AlGaN} / \mathrm{GaN}$ heterostructures. On the other hand, the strain relaxation leads to more roughness on the surface [18]. Therefore, a rougher surface of B-027 than that of B-060 may be caused by an elastic strain relaxation formation at the interface. Below $100 \mathrm{~K}$, where the carrier confinement is much better, the strain relaxation in B-027 can cause a lower 2DEG mobility and a lower 2DEG sheet carrier density. So the difference in the low-temperature mobilities is limited with interface roughness scattering, which is related to roughness caused by strain relaxation. The measured and calculated properties of studied undoped $\mathrm{Al}_{0.25} \mathrm{Ga}_{0.75} \mathrm{~N} / \mathrm{GaN}$ heterostructures are given in Table 1.

\section{Conclusion}

Two-step growth undoped $\mathrm{Al}_{0.25} \mathrm{Ga}_{0.75} \mathrm{~N} / \mathrm{GaN}$ heterostructures with semi-insulating buffer were grown by MOCVD. The Hall effect measurements of the samples were carried out as a function of temperature $(20-350 \mathrm{~K})$ and magnetic field density $(0-1.5 \mathrm{~T})$. Magnetic fielddependent Hall data were analyzed using the QMSA method. The analyses showed that there was strong 2DEG localization below $100 \mathrm{~K}$ and there was no significant parallel conduction in either sample. In the absence of parallel conduction, it was shown that in-plain and growthaxis strains can be calculated using the total polarizationinduced charge density taken as the sheet carrier density measured from the conventional Hall effect. The calculated strain values are in good agreement with the literature. Relation between strain and growth conditions is also discussed. It has been shown that higher annealing temperature leads to less strain at the $\mathrm{Al}_{0.25} \mathrm{Ga}_{0.75} \mathrm{~N} / \mathrm{GaN}$ interface. Reduction in the strain is due to elastic strain relaxation at $\mathrm{Al}_{0.25} \mathrm{Ga}_{0.75} \mathrm{~N} / \mathrm{GaN}$ interface that directly affect the crystalline quality of the material. The strain relaxation results in more roughness on surface and at $\mathrm{Al}_{0.25} \mathrm{Ga}_{0.75} \mathrm{~N} / \mathrm{GaN}$ interface, lower $2 \mathrm{DEG}$ sheet carrier density, and a lower mobility structure. A successful method was shown herein that provides reliable strain information using only Hall measurements for undoped $\mathrm{AlGaN} / \mathrm{GaN}$ heterostructures.

\section{Acknowledgments}

This work is supported by the State of Planning Organization of Turkey under Grant No. 2001K120590, and by TUBITAK under Project Nos. 104E090, 105E066, and 105A005. One of the authors (Ekmel Özbay) acknowledges partial support from the Turkish Academy of Sciences.

\section{References}

[1] Y.F. Wu, B.P. Keller, S. Keller, D. Kapolnek, P. Kozodoy, S.P. Denbaars, U.K. Mishra, Appl. Phys. Lett. 69 (1996) 1438.

[2] M.A. Khan, Q. Chen, J.W. Yang, M.S. Shur, B.T. Dermott, J.A. Higgins, IEEE Electron. Device Lett. 17 (1996) 325.

[3] M.S. Shur, M.A. Khan, MRS Bull. 22 (1997) 44.

[4] O. Aktas, Z.F. Fan, A. Botchkarev, S.N. Mohammad, M. Roth, T. Jenkins, L. Kehias, H. Morkoç, IEEE Electron. Device Lett. 18 (1997) 293.

[5] Y.F. Wu, B.P. Keller, P. Fini, S. Keller, T.J. Jenkins, L.T. Kehias, S.P. Denbaars, U.K. Mishra, IEEE Electron. Device Lett. 19 (1998) 50.

[6] U.K. Mishra, Y.F. Wu, B.P. Keller, S. Keller, S.P. DenBaars, IEEE Trans. Microw. Theory 46 (1998) 756.

[7] R. Li, S.J. Cai, L. Wong, Y. Chen, K.L. Wang, R.P. Smith, S.C. Martin, K.S. Boutros, J.M. Redwing, IEEE Electron. Device Lett. 20 (1999) 323.

[8] U.K. Mishra, J.C. Zolper (Eds.), IEEE Trans. Electron. Dev. 48 (2001) 405.

[9] P. Kordos, in: Proceedings of 3rd International EuroConference on Advanced Semiconductor Devices and Microsystems, Slovakia, 2000, p. 47.

[10] L. Sugiura, K. Itaya, J. Nishio, H. Fujimoto, Y. Kokubun, J. Appl. Phys. 82 (1997) 4877.

[11] P.W. Yip, S.Q. Wang, A.J. Drehman, L.D. Zhu, P.E. Norris, Mater. Res. Soc. Symp. Proc. 482 (1998) 93.

[12] L. Cheng, G. Zhang, D. Yu, Z. Zhang, Appl. Phys. Lett. 70 (1997) 1408.

[13] X.H. Wu, D. Kapolnek, E.J. Tarsa, B. Heying, S. Keller, B.P. Keller, U.K. Mishra, S.P. Denbaars, J.S. Speck, Appl. Phys. Lett. 68 (1996) 1371.

[14] A. Munkholm, C. Thompson, C.M. Foster, J.A. Eastman, O. Auciello, G.B. Stephenson, P. Fini, S.P. DenBaars, J.S. Speck, Appl. Phys. Lett. 72 (1998) 2972.

[15] Y. Zhang, J. Singh, J. Appl. Phys. 85 (1999) 587.

[16] O. Ambacher, et al., J. Appl. Phys. 85 (1999) 3222.

[17] J. Antoszewski, M. Gracey, J.M. Dell, L. Faraone, T.A. Fisher, J. Appl. Phys. 87 (2000) 3900.

[18] A. Bourret, C. Adelmann, B. Daudin, J.L. Rouvière, G. Feuillet, G. Mula, Phys. Rev. B 63 (2001) 245307.

[19] J.H. Lee, M.B. Lee, S.H. Hahm, Y.H. Lee, J.H. Lee, Y.H. Bae, H.K. Cho, MRS Internet J. Nitride Semicond. Res. 8 (2003) 5.

[20] H. Yu, D. Caliskan, E. Ozbay, J. Appl. Phys. 100 (2006) 033501.

[21] O. Ambacher, et al., J. Appl. Phys. 87 (2000) 334.

[22] F. Calle, T. Palacios, E. Monroy, J. Grajal, M. Verdu, Z. Bougrioua, I. Moerman, J. Mater. Sci.-Mater. Electron. 14 (2003) 271.

[23] Z. Dziuba, J. Antoszewski, J.M. Dell, L. Farone, P. Kozodoy, S. Keller, B. Keller, S.P. Denbaars, U.K. Mishra, J. Appl. Phys. 82 (1997) 2996. 
[24] J. Antoszewski, L. Faraone, Opto-Electron. Rev. 12 (2004) 347.

[25] B.K. Ridley, J. Appl. Phys. 84 (1998) 4020.

[26] I.P. Smorchkova, et al., J. Appl. Phys. 86 (1999) 4520.

[27] S.B. Lisesivdin, S. Acar, M. Kasap, S. Ozcelik, S. Gokden, E. Ozbay, Semicond. Sci. Technol. 22 (2007) 543.
[28] B. Shen, T. Someya, Y. Arakawa, Appl. Phys. Lett. 76 (2000) 2746.

[29] A.E. Wickenden, D.K. Wickenden, T.J. Kistenmacher, J. Appl. Phys. 75 (1994) 5367.

[30] H. Iwanaga, A. Kunishige, S. Takeuchi, J. Mater. Sci. 35 (2000) 2451. 